\title{
WOMEN IN CANCER THEMATIC REVIEW \\ Diverse functions of DNA methylation: implications for prostate cancer and beyond
}

\author{
Thomas J Sweet and Angela H Ting
}

Genomic Medicine Institute, Lerner Research Institute, Cleveland Clinic, Cleveland, Ohio, USA

Correspondence should be addressed to A H Ting

Email

tinga@ccf.org

\begin{abstract}
Prostate cancer is one of the most common malignancies in men worldwide. Current clinical screening ensures that most prostate cancers are diagnosed while still organ confined, but disease outcome is highly variable. Thus, a better understanding of the molecular features contributing to prostate cancer aggressiveness is being sought. For many cancers, aberrant genome-wide patterns of cytosine DNA methylation in CpG dinucleotides distinguish tumor from normal tissue and contribute to disease progression by altering the transcriptome. In prostate cancer, recent genomic studies identified cancer and high grade-specific differential DNA methylation in gene promoters, gene bodies, gene $3^{\prime}$ ends and at distal regulatory elements. Using examples from developmental and disease systems, we will discuss how DNA methylation in each of these genomic contexts can contribute to transcriptome diversity by modulating transcription initiation, alternative transcription start site selection, alternative pre-mRNA splicing and alternative polyadenylation. Alternative transcripts from the same gene often exhibit altered protein-coding potential, translatability, stability and/or localization. All of these can have functional consequences in cells. In future work, it will be important to determine if DNA methylation abnormalities in prostate cancer modify the transcriptome through some or all of these mechanisms and if these DNA methylation-mediated transcriptome alterations impact prostate tumorigenesis and aggressiveness.
\end{abstract}

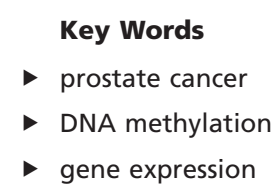

Endocrine-Related Cancer (2016) 23, T169-T178

\section{Introduction}

\section{Prostate cancer genomics}

Prostate cancer is the most common non-skin cancer malignancy among American men and the second most common among men worldwide (Siegel et al. 2015). Both genetic and demographic factors contribute to the high incidence of prostate cancer (Al Olama et al. 2014). Clinically, elevated prostate-specific antigen (PSA) in the blood serves as an early marker for prostate cancer; early detection has led to approximately $90 \%$ of prostate cancers still being localized to the prostate at the time of diagnosis (Penney et al. 2013). However, disease outcome is highly variable on a spectrum ranging from indolent disease that can be monitored by active surveillance to highly aggressive disease that leads to death.

A useful predictor of prostate cancer aggressiveness is the Gleason grade (Epstein et al. 1996, Albertsen et al. 1998, Pan et al. 2000, Penney et al. 2013). The presence of Gleason pattern 4/5 cancers is associated with increased development of metastatic disease, morbidity and

This paper is part of a special section on Celebrating Women in Cancer Research. The Guest Editors for this section were Charis Eng and Deborah Marsh. 
mortality compared with Gleason 3 cancers (Stamey et al. 1999, Humphrey 2004). However, the majority of cases contain a mixture of low- and high-grade cancers making it difficult to define the risks. In the absence of accurate prediction of aggressiveness, patients and clinicians justifiably err on the side of caution; recent estimates are that 37 patients still need treatment to prevent 1 death (Schroder et al. 2012). Such over-treatment is of concern because radical therapies like prostatectomy and radiation have serious side effects that significantly impair the quality of life. Thus, a major goal of prostate cancer research is to find other parameters that inform on disease aggressiveness.

Molecular features are one promising avenue that is being explored. Using genome-wide mutation, somatic copy number alterations, DNA methylation, mRNA expression and miRNA expression data from 333 prostate cancer specimens, The Cancer Genome Atlas (TCGA) identified a number of mutations that could stratify prostate cancer into subtypes for potential targeted therapies (Cancer Genome Atlas Research 2015). For example, $19 \%$ of prostate cancers had defects in DNA repair genes, and this subset of cancers may respond to PARP inhibitors as suggested by an independent study (Robinson etal. 2015). Further, genes that affect MAP kinase or phosphatidylinositol 3-kinase pathways were mutated in roughly $25 \%$ of prostate cancers, for which some lesions are predicted to confer sensitivity to particular pathway inhibitors (Dahlman et al. 2012, Bowyer et al. 2014). The TCGA study also found associations between molecular features and aggressiveness as categorized by the Gleason score, which is the sum of the most dominant and second most dominant Gleason grade patterns seen in a prostate cancer specimen. In addition to confirming a known positive correlation between DNA copy number variation and Gleason score, integration of DNA and RNA features revealed particular clusters of disease that correlate with Gleason score. Although this study ultimately concluded that no single parameter can accurately predict aggressiveness, it does raise the intriguing possibility that integrating several levels of molecular data, including DNA methylation, may provide better biological insights.

In prostate cancer, DNA methylation has been evaluated as a means to identify cancerous tissue and to discern the aggressiveness of tumors. Early work discovered that assaying tumor DNA for methylation of glutathione S-transferase pi 1 (GSTP1) promoter can identify prostate cancer (Lin et al. 2001, Gonzalgo et al. 2004). More recently, multigene panels of DNA methylation are suggested to provide information on aggressiveness (Valdes-Mora \& Clark 2015). One limitation of the TCGA work described previously is that it used DNA methylation data from the Infinium Human Methylation 450 Bead Chip array that only assays a small portion of all possible DNA methylation sites in the human genome. Using methyl-CpG-binding domain (MBD)-isolated genome sequencing, a technique which provides more comprehensive coverage of the mappable genome (Serre et al. 2010), we more fully explored the relationship between prostate cancer aggressiveness and genome-wide DNA methylation patterns in a cohort consisting of benign prostates, low-grade cancers (exclusively Gleason grade 3 ) and high-grade cancers (exclusively Gleason grade 4/5) (Bhasin et al. 2015). We identified both cancer-specific and high Gleason grade-specific DNA methylation. These differentially methylated regions (DMRs) are observed throughout the genome in both coding and non-coding sequences and prompted us to consider the functions of DNA methylation in the different genomic contexts to help shed light on prostate cancer biology.

\section{DNA methylation}

The DNA methylation discussed in this review refers to the covalent addition of a methyl group to the 5 th position of cytosine within $\mathrm{CpG}$ dinucleoties (Fig. 1). In mice and men, DNA methylation is catalyzed by DNA methyltransferases (DNMTs), where de novo activity is largely conferred by DNMT3a and DNMT3b, and maintenance function during DNA replication is carried out by DNMT1 (Bestor 1988, Li et al. 1992, Lei et al. 1996, Okano et al. 1998, Kaneda et al. 2004). On the other hand, active erasure of DNA methylation is achieved by ten-eleven translocation (tet) methylcytosine dioxygenases (TETs). TET enzymes convert 5-methylcytosine to 5-hydroxymethylcytosine and subsequently to formyl or carboxyl cytosine, which is excised by thymine-DNA glycosylase (TDG) and repaired with an unmodified cytosine (Tahiliani et al. 2009, He et al. 2011, Ito et al. 2011). Whether the oxidized derivatives of methylcytosine harbor distinct biological functions and the cues that direct these methyltransferases and demethylases to particular genomic regions to regulate DNA methylation are areas of active research.

CpG-methylated DNA has different properties than unmethylated DNA. For example, binding of a wide range of transcription factors, chromatin modifiers and DNA repair enzymes to DNA is sensitive to DNA methylation status (Hu et al. 2013). Functionally, this has profound consequences, as DNA methylation status in turn influences transcription and associated processes

Published by Bioscientifica Ltd 


\section{DNMTs}

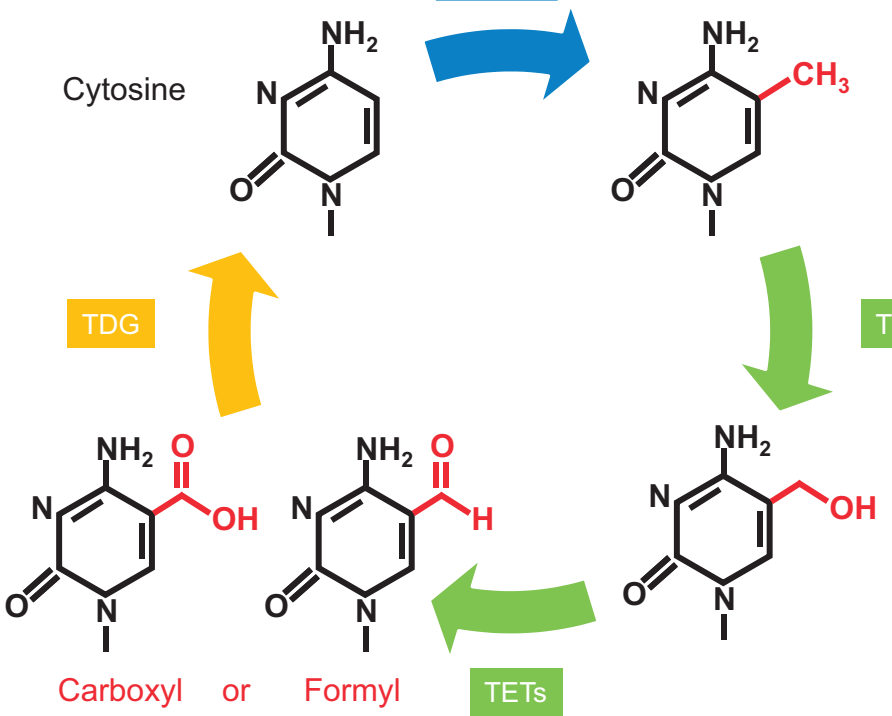

such as RNA expression, RNA processing, higher order genome structure and genomic stability. Underscoring the regulatory potential of DNA methylation, different cell types exhibit different genome-wide patterns of DNA methylation within the same tissue, across different tissues and between diseased states and their normal
Methyl

\section{Figure 1}

The cycle of DNA methylation addition and removal. A model for how DNA methylation is added and removed from the 5th position of cytosine is presented. Clockwise from cytosine: cytosine is converted to methylcytosine by DNA methyltransferases (DNMTs), and demethylated by successive conversion to hydroxymethylcytosine then formylcytosine or carboxycytosine carried out by ten-eleven translocation (TET) methylcytosine dioxygenases.

Hydroxymethyl Then as part of the base excision repair pathway, thymine-DNA glycosylase (TDG) excises formylcytosine or carboxycytosine from the DNA. The DNA is repaired with an unmodified cytosine to complete the demethylation cycle.

counterparts. With respect to mRNA expression, DNA methylation has been most extensively studied as a mechanism to silence gene promoters. However, DNA methylation is also present throughout the genome, and recent work shows widely varied functions dependent upon the genomic context of DNA methylation (Fig. 2).

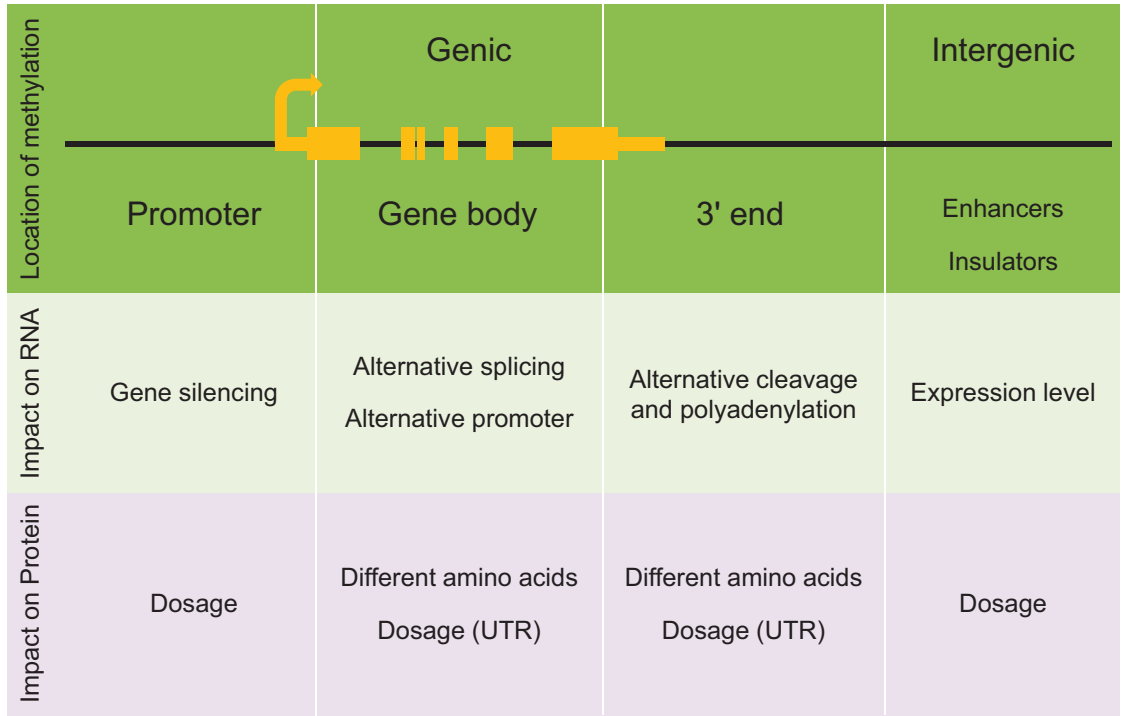

Figure 2

DNA methylation has diverse gene regulatory functions depending upon genomic context. A simplified model of the genome is depicted at the top (green box). The yellow rectangles are exons of a generic mRNA-producing gene, and the black lines between exons are introns. Thin yellow exonic regions correspond to untranslated regions (UTR) of mRNA, and thick yellow exonic regions correspond to protein coding mRNA sequences. The black lines outside of the genic region depict intergenic DNA. Within each genomic context, the first row below indicates known, context-specific functions of DNA methylation on mRNA expression (light green box). The second row below indicates how these effects on mRNA expression translate to altered protein expression (pink box). It is important to note that this figure does not imply evidence exists for each of these mechanisms specifically in prostate cancer. Instead, it serves to summarize known functions of DNA methylation studied in a wide range of biological systems and suggests that prostate cancer-specific DNA methylation found in each of these contexts may function through some or all of these mechanisms. 
For the rest of this review, we will discuss how DNA methylation impacts mRNA expression and pre-mRNA processing in each of these genomic contexts in multiple systems to better highlight the roles that cancer- and high grade-specific DNA methylation may play in prostate cancer biology.

\section{Context-dependent functions of DNA methylation}

\section{Promoter methylation}

Mammalian gene promoters are DNA sequences that stimulate transcription initiation. In this review, we will focus on gene promoters that produce messenger RNA by recruiting RNA polymerase II. Approximately half of the known mammalian promoters are GC rich and CpG dense relative to the genomic background. This CpG-dense configuration of DNA, known as a CpG island (CGI), helps promote a nucleosome-depleted state at promoters when CGIs are unmethylated (Illingworth \& Bird 2009, Deaton $\&$ Bird 2011). CGIs and the 2 kilobases flanking CGIs (CGI shores) often contain DNA regulatory elements that can modulate transcription initiation by RNA polymerase II, and the methylation status of these elements can impact the transcriptional activity at these gene promoters.

Although unmethylated CGIs are most often associated with competency to initiate transcription, methylation of promoter CGI can silence the expression of genes. Convincing evidence that methylated CpGs near a transcription start site can directly participate in silencing was provided by site-specific alteration of DNA methylation in native chromatin (Maeder et al. 2013) and minimal promoter reporter constructs (Klug \& Rehli 2006, Han et al. 2013). Promoter silencing by DNA methylation occurs by at least two paradigms. First, many transcription activators are known to preferentially bind to an unmethylated DNA-binding site (Hu et al. 2013). For example, methylation of n-Myc DNA-binding sites (E-boxes) within gene promoters limits the recruitment of $\mathrm{n}-\mathrm{Myc}$ to activate transcription from several genes, including EGFR (Perini et al. 2005). A second mode of regulation involves increased binding of repressive methylCpG-binding domain (MBD) proteins to methylated CGI promoters (Parry \& Clarke 2011). MBDs in turn can recruit proteins such as histone deacetylases (HDACs) that remove acetyl groups from histones, which allows for compaction of promoter chromatin and silencing of gene expression.
There are now countless examples of promoter silencing by DNA methylation, including silencing of germ cell- (Maatouk et al. 2006), pluripotency- and differentiation-associated genes (Boland et al. 2014). Additionally, in most cancer types, aberrant DNA methylation of gene promoters can effectively silence tumor suppressor genes. The list of tumor suppressor genes silenced by promoter DNA methylation is extensive and growing and includes classical tumor suppressor genes such as RB, APC, BRCA1 and MLH1 (Baylin 2005). Whether DNA methylation reinforces a pre-existing silenced state or plays a role in initial silencing remains to be solidified. Experiments involving DNA methylationmediated inactivation of the X-chromosome (Chaligne $\&$ Heard 2014), of tumor suppressor genes in cancer cells (Bachman et al. 2003), and of genes during cellular reprogramming (Papp \& Plath 2013) suggest that the silenced state occurs first, and DNA methylation serves to reinforce and maintain silencing.

Although repression of promoter CGI is the most well-documented function of DNA methylation in gene expression, it is not the only function of DNA methylation at promoters. Examples of promoter CGI methylation associated with gene activation also exist. In one case, cyclical methylation of the $p S 2$ gene promoter is associated with transcriptional activation of $p S 2$ by estrogen receptor alpha (Kangaspeska et al. 2008, Metivier et al. 2008). In another case, FOXA2 gene activation is associated with DNA methylation-mediated block of repressor binding to its promoter, and this activation can be suppressed by an inhibitor of DNMT1 or by knockdown of DNMT3b (Bahar Halpern et al. 2014).

It is also important to note that the majority of genes exhibiting differential promoter methylation between cellular states do not exhibit differential gene expression (Moarii etal.2015). These changes in promoter methylation could have more complex effects. As promoter state can modulate post-initiation events such as RNA processing (Ji et al. 2011), an interesting hypothesis is that promoter methylation can influence downstream steps of gene expression. Although we have a great deal of knowledge about how DNA methylation can silence promoters, there is still much to be learned about how DNA methylation can activate promoters and potentially affect other steps of gene expression.

The list of gene promoters that are found to be methylated in prostate cancer is long and has been extensively reviewed elsewhere (Day \& Bianco-Miotto 2013). One classical example is methylation of glutathione

Published by Bioscientifica Ltd. 
S-transferase pi 1 (GSTP1) promoter, which occurs in the majority of prostate cancer samples (Lin et al. 2001). GSTP1 encodes an enzyme that is involved in detoxification and metabolism of a wide range of carcinogens as well as steroid hormones (Katoh et al. 2008). Loss of GSTP1 function in the prostate may allow for increased carcinogenic insult and/or improper hormonal signaling, contributing to prostate cancer progression. Furthermore, GSTP1 promoter methylation has shown utility for prostate cancer diagnosis and prognostication. As such, it is part of a multigene panel that is now clinically used (ConfirmMDx) on prostate cancer biopsies for diagnosing localized disease.

\section{Gene body methylation}

In the last section, we focused on the most well-studied case: promoter DNA methylation and its relationship with gene expression. However, DNA methylation also occurs throughout gene bodies. In contrast to promoter methylation, gene body methylation more often positively correlates with gene expression, but its functions are less characterized (Lister et al. 2009, Lou et al. 2014). Studies over the last several years have linked gene body DNA methylation to diversification of the transcriptome through mechanisms including alternative transcription start site selection, alternative splicing and alternative polyadenylation site selection. These alternative transcripts can greatly expand the proteome by encoding different polypeptides. Additionally, alternative transcripts can have unique untranslated regions, which can control translatability, stability and/or localization of mRNA. Major goals of gene expression research include how alternative transcript isoforms are generated and the functionality of unique transcript isoforms. In the following sections, we will discuss the current evidence from many systems that support the functional roles for gene body DNA methylation in modulating alternative transcription start sites, alternative pre-mRNA splicing and alternative polyadenylation.

\section{Alternative transcription start sites}

Several studies have detected $\mathrm{m} 7 \mathrm{G}$ capped $5^{\prime}$ ends of transcripts from many more intragenic regions than would be predicted by known protein and non-coding gene databases (Yamashita et al. 2011, Consortium et al. 2014). Although some may be 'transcriptional noise', others reflect bona fide activity of previously unannotated promoters within gene bodies. Transcription initiations from these cryptic promoters yield mRNA transcripts with different $5^{\prime}$ end sequences. Many unmethylated gene body CGIs had histone H3 lysine 4 trimethylation (H3K4me3) and CAGE tags originating nearby, both of which are features of sequences surrounding transcription start sites (TSSs) (Maunakea et al. 2010). Subsequent experiments demonstrated that DNA methylation can influence alternative TSS selection through its influence on gene body CGI promoter activity, presumably via analogous mechanisms detailed for annotated gene promoters (Maunakea et al. 2010, Nagarajan et al. 2014). Studies of the SHANK3 gene that is important for neural development and is defective in several neurological syndromes suggest that demethylation drives the upregulation of alternative TSS. When DNA methylation is removed from gene body CGIs in SHANK3 using 5-aza2'-deoxycytidine, transcription initiates from these CGIs, creating unique 5' ends for SHANK3 transcripts (Maunakea et al. 2010). It remains unknown whether these alternative transcripts are actually functional, simply serve to limit the production of full-length transcript or if both occurs. Interestingly, differential DNA methylation across tissues is more prevalent in gene body CGIs than at CGIs near the $5^{\prime}$ end of the genes, suggesting that the influence of DNA methylation on alternative TSS selection may have greater developmental consequences.

Alternative TSS regulation by DNA methylation at RASSF1 and APC has been reported in prostate cancer tissue and shown by treatment of cells with 5-aza-2'deoxycytidine (Massie et al. 2016). Another intriguing example is prostate cancer-specific demethylation of an internal promoter in MCT2 (Pertega-Gomes et al. 2015). Utilization of this alternative promoter alters the $5^{\prime}$ untranslated region of MCT2 mRNA and leads to MCT2 protein overexpression, which in turn contributes to prostate cancer cell growth.

\section{Alternative pre-mRNA splicing}

RNA polymerase II transcripts are initially generated as premature mRNA (pre-mRNA) containing both exons and introns. Introns are then removed, and exons are spliced together by the spliceosome to generate mature mRNA. Not all exons are constitutively included in mature mRNA; instead, exon inclusion is heavily regulated in tissue- and cell type-specific manners (Licatalosi \& Darnell 2010). Alternative pre-mRNA splicing (AS) refers to the process of selecting exons that are to be included in a mature mRNA. The vast majority of genes undergo AS, and

Published by Bioscientifica Ltd 
AS is a mechanism for greatly expanding the transcriptome and proteome. RNA factors, DNA factors, chromatin factors and RNA polymerase II elongation rate are known to influence splicing decisions either separately or in combination (Luco et al. 2011). Observations of enhanced DNA methylation across mammalian exons have led to the hypothesis that DNA methylation can influence splicing by recruiting either RNA or DNA factors, changing local chromatin, or influencing RNA polymerase II transit (Gelfman et al. 2013, Singer et al. 2015).

One example of a splicing event regulated by DNA methylation is CD45 exon 5 inclusion (Shukla et al. 2011). Exon 5 of CD45 encodes a glycosylated extracellular domain important for signaling, and exon 5 is retained in peripheral lymphocytes until late in development. Exon 5 is included in the mature mRNA when a downstream region is occupied by CCCTC-binding factor (CTCF). CTCF binding at this location likely causes RNA polymerase II pausing, and this pausing presumably allows time for recognizing and utilizing the 'weak' cis-acting splicing sequences at exon 5. Importantly, this only occurs when the DNA binding site for CTCF is unmethylated because CTCF binding to DNA is blocked by DNA methylation (Wang et al. 2012). Therefore, when this same region is methylated in B cells, CTCF cannot bind resulting in a relatively rapid RNA polymerase II transit and exon 5 exclusion. More recent genomic analyses after this initial observation estimated that about 200 genes had exons regulated by this mechanism (Marina et al. 2016).

Another example that links DNA methylation, chromatin state and transcription rate with alternative splicing involves methyl-CpG-binding protein 2 (MECP2), a protein that preferentially binds methylated DNA. Maunakea and coworkers demonstrated that inclusion of certain exons depends on DNA methylationmediated recruitment of MECP2 and that MECP2 binding correlates with decreased histone acetylation and increased RNA polymerase II occupancy at these exons (Maunakea et al. 2013). Likely, MECP2 sets up a chromatin and transcriptional state conducive to exon inclusion. One final example of DNA methylation regulating alternative splicing implicates heterochromatin protein 1 (HP1)-mediated recruitment of a pre-mRNA-binding protein (Yearim et al. 2015). Here, DNA methylation promotes histone $\mathrm{H} 3$ lysine 9 trimethylation (H3K9me3), which in turn recruits HP1 to exons. HP1 then recruits SRSF3 RNA-binding protein to the pre-mRNA to exclude a nearby exon. Genomic surveys revealed this mechanism to regulate at least 84 exons that are present in genes enriched for cell differentiation processes.
Perturbation of RNA polymerase II elongation rate at these loci was not assessed.

Although none has been linked to a DNA methylationregulated mechanism, alternative splicing is widespread in prostate cancer (Lapuk et al. 2014). One clinically relevant example is the loss of the androgen receptor (AR) ligand-binding domain by splicing. This alternative splicing event renders prostate tumors insensitive to drugs that target the AR ligand-binding domain (Guo et al. 2009). Since prostate cancer and high grade-specific DMRs occur throughout gene bodies (Bhasin et al. 2015), an interesting future direction will be to test if DNA methylation regulates splicing.

\section{Alternative polyadenylation (APA)}

In concert with RNA polymerase II transcription termination, 3' ends of mature mRNA transcripts are generated by cleavage and polyadenylation of premRNA. These RNA processing steps are carried out co-transcriptionally by several protein complexes (Elkon et al. 2013). In recent years, it has become appreciated that most mammalian genes encode multiple possible sites of cleavage and polyadenylation. Selection of polyadenylation sites (alternative polyadenylation or APA) is tissue and cell type dependent and contributes to transcript diversity by changing protein coding sequences and/or 3' untranslated regions (3' UTRs), which can lead to changes in mRNA stability, translatability or localization (Di Giammartino et al. 2011). Similar to splicing, alternative polyadenylation is likely influenced by some combination of RNA factors, DNA factors, chromatin factors and RNA polymerase II elongation rate.

At the $\mathrm{H13}$ and Herc3 loci in mouse, gene body DNA methylation has been shown to modulate APA (Wood et al. 2008, Cowley et al. 2012). H13 has a retrogene embedded within an intron in the sense orientation, whereas Herc3 has a retrogene embedded within an intron in the antisense orientation. On one allele, the retrogene's promoter (also encoded in the intron) is silenced by DNA methylation, and the most distal polyadenylation site in the host gene is used, producing full-length H13 and Herc 3 mRNAs and proteins. On the other allele, the retrogene's promoter is unmethylated, transcription initiates within each host gene and polyadenylation sites upstream of the retrogene are used, generating truncated H13 and Herc3 mRNAs and proteins. Although the mechanistic details are yet to be worked out (i.e., whether transcription interference is occurring or differentially methylated DNA is helping to differentially recruit polyadenylation factors), these

Published by Bioscientifica Ltd. 
studies clearly show that DNA methylation can influence APA by linking allele-specific DNA methylation with allele-specific APA in the same cell.

Although cases of DNA methylation-regulated APA have not been reported in prostate cancer, APA does occur, and 3' UTR lengths in select genes, including $R U N X 1, M Y C, K L K 2$ and $K L K 3$, could cluster tumors into risk categories (Li et al. 2014). As prostate cancer and high grade-specific DMRs occur near 3' ends of genes (Bhasin et al. 2015), determining if DNA methylation regulates alternative polyadenylation could provide novel disease insights.

\section{Distal regulatory elements}

It is now widely accepted that DNA elements far away on the linear chromosome can influence gene expression (Heintzman \& Ren 2009). Classically, these elements are categorized as enhancers, which can come into close proximity to activate promoters, or insulators, which can keep enhancers away from promoters. Each of these regulatory elements can be regulated by DNA methylation to confer gene expression changes.

\section{Enhancers}

Enhancers are thought to loop into close spatial proximity to promoters to help activate transcription through a variety of mechanisms, including but not limited to recruitment of transcriptional activators, RNA polymerase II and chromatin-modifying enzymes (Blackwood \& Kadonaga 1998, Shlyueva et al. 2014). Enhancer RNA (eRNA) is often produced from the enhancer region by RNA polymerase II, but whether eRNA is essential for enhancer function may be locus dependent. Superenhancers are proposed to be clusters of enhancers, each of which is required in combination to activate genes, but the requirement that the combinatorial action of all enhancers in the cluster is needed for activation is still under investigation (Pott \& Lieb 2015).

Several studies showed that enhancers can be regulated by DNA methylation. One study using The Cancer Genome Atlas datasets found inverse correlations between DNA methylation of enhancers and putative enhancer-regulated gene expression across many cancer types (Yao et al. 2015). This included potential for silencing many tumor suppressor genes by cancerspecific enhancer hypermethylation as well as activation of many oncogenes by cancer-specific enhancer hypomethylation. Independently, a comparison of a wide range of normal tissues, cancer tissues and cultured cells suggested that super-enhancer DNA is aberrantly hypomethylated across many cancer types, with potential activating effects on oncogenes such as MYC and RNF43 (Heyn et al. 2016). Lastly, intragenic DNA methylation in HCT116 colon cancer cells was shown to silence intronic enhancers, leading to reduced expression of the gene harboring the silenced enhancer (Blattler et al. 2014). Although interesting, these studies were largely correlative, and it will be neccessary to emperically test enhancer and super-enhancer regions for the direct regulation of putative target genes and sensitivity to DNA methylation.

In prostate cancer, many enhancers are predicted to change activity (Taberlay et al. 2014), including the androgen-responsive enhancers that control the expression of PSA (Lawrence et al. 2012). Importantly, activity changes in a subset of enhancers correlate with the DNA methylation status over the enhancers (Taberlay et al. 2014), and work from our group detected cancer and high grade-specific DMRs at putative enhancers in prostate and prostate cancer (Bhasin et al. 2015). Additionally, TSS and CGI DNA methylation are relatively static throughout a prostate cancer, but enhancer DNA methylation is highly variable among different foci within the same cancer (Brocks et al. 2014). These observations suggest the intriguing possibility that DNA methylation contributes to the heterogeneity in prostate cancer biology and clonality via enhancer regulation.

\section{Insulators}

Insulators are DNA elements that define boundaries of enhancer reach. When functional, insulators keep enhancers from coming into proximity with gene promoters by changing higher order DNA structure. The classical example of insulator regulation by DNA methylation is the imprinting of the IGF2/H19 region (Soejima \& Higashimoto 2013). The paternal allele exhibits methylation that blocks CTCF-mediated insulation between $H 19$ and IGF2, allowing enhancers near H19 to upregulate IGF2. On the maternal allele, CTCF occupies its unmethylated binding site between the genes and insulates IGF2 from these same enhancers, resulting in the silencing of maternal IGF2 allele and upregulation of H19 instead. Loss of IGF2/H19 imprinting, where both alleles are methylated, leads to the overexpression of IGF2 and IGF2-mediated cellular overgrowth, which are the molecular underpinnings of Beckwith-Wiedemann syndrome and Wilms' tumor (Leick et al. 2012).

Published by Bioscientifica Ltd 
The methylation of insulators in cancer cells, including prostate cancer cells, has been shown to correlate with changes in their chromatin configuration (Taberlay et al. 2014). Specifically, insulators acquiring DNA methylation in both prostate and breast cancer cell systems exhibited chromatin parameters indicative of insulator silencing. Perhaps the most convincing example to date of DNA methylation-mediated insulator silencing is in gliomas. $I D H$-mutant gliomas acquire DNA methylation at insulator elements that prevent CTCFmediated insulator function (Flavahan et al. 2016). One particular insulator that is silenced ultimately leads to the overexpression of oncogenic PDGFRA. The CTCF-binding site within the insulator sequence was mutated using CRISPR in IDH WT glioma cells, where this insulator is unmethylated and occupied by CTCF. This perturbation abolished CTCF binding, nullified insulator function and subsequently drove PDGFRA overexpression and cell proliferation. In other words, the silencing of CTCFmediated insulator function by DNA methylation seen in $I D H$-mutant gliomas could be phenocopied by destroying the insulator's unmethylated, occupied CTCF-binding site in IDH WT cells.

\section{Summary/future directions}

DNA methylation is a versatile modification that is of great interest because genome-wide patterns of DNA methylation are implicated in 'locking in' of cellular fates. Indeed, aberrant methylation patterns seen in virtually every type of cancer, including prostate cancer, are thought to contribute to malignant phenotypes. In addition, aberrant methylation of particular gene subsets can serve as biomarkers. Despite the wealth of information about silencing tumor suppressor gene promoters in prostate cancer, there is much to be learned about DNA methylation in other genomic contexts. Indeed, our own work has identified prostate cancerspecific and high grade-specific DMRs enriched in other genomic compartments, including in gene bodies, and at gene $3^{\prime}$ ends, genic locations where alternative RNA isoform production is regulated via alternative TSS, splicing and 3' end formation. Also, DMRs are enriched at enhancers that are active in prostate and prostate cancer. As alternative RNA isoform production and regulation of gene expression by distal elements have been shown to occur in prostate cancer cells or tissue, the challenge now is to establish the functional relevance and clinical utility of prostate cancer and high grade-specific DMRs in each genomic context (Fig. 2).
Declaration of interest

The authors declare that there is no conflict of interest that could be perceived as prejudicing the impartiality of this review.

\section{Funding}

This work was supported by the National Cancer Institute of the National Institutes of Health (grant number R01CA154356) and the VeloSano Pilot Award.

\section{References}

Al Olama AA, Kote-Jarai Z, Berndt SI, Conti DV, Schumacher F, Han Y, Benlloch S, Hazelett DJ, Wang Z, Saunders E, et al. 2014 A metaanalysis of 87,040 individuals identifies 23 new susceptibility loci for prostate cancer. Nature Genetics 46 1103-1109. (doi:10.1038/ng.3094)

Albertsen PC, Hanley JA, Gleason DF \& Barry MJ 1998 Competing risk analysis of men aged 55 to 74 years at diagnosis managed conservatively for clinically localized prostate cancer. JAMA $\mathbf{2 8 0}$ 975-980. (doi:10.1001/jama.280.11.975)

Bachman KE, Park BH, Rhee I, Rajagopalan H, Herman JG, Baylin SB, Kinzler KW \& Vogelstein B 2003 Histone modifications and silencing prior to DNA methylation of a tumor suppressor gene. Cancer Cell $\mathbf{3}$ 89-95. (doi:10.1016/S1535-6108(02)00234-9)

Bahar Halpern K, Vana T \& Walker MD 2014 Paradoxical role of DNA methylation in activation of FoxA2 gene expression during endoderm development. Journal of Biological Chemistry 289 23882-23892. (doi:10.1074/jbc.M114.573469)

Baylin SB 2005 DNA methylation and gene silencing in cancer. Nature Clinical Practice Oncology 2 (Supplement 1) S4-S11. (doi:10.1038/ ncponc0354)

Bestor TH 1988 Cloning of a mammalian DNA methyltransferase. Gene 74 9-12. (doi:10.1016/0378-1119(88)90238-7)

Bhasin JM, Lee BH, Matkin L, Taylor MG, Hu B, Xu Y, Magi-Galluzzi C, Klein EA \& Ting AH 2015 Methylome-wide sequencing detects DNA hypermethylation distinguishing indolent from aggressive prostate cancer. Cell Reports 13 2135-2146. (doi:10.1016/i.celrep.2015.10.078)

Blackwood EM \& Kadonaga JT 1998 Going the distance: a current view of enhancer action. Science $\mathbf{2 8 1}$ 60-63. (doi:10.1126/ science.281.5373.60)

Blattler A, Yao L, Witt H, Guo Y, Nicolet CM, Berman BP \& Farnham PJ 2014 Global loss of DNA methylation uncovers intronic enhancers in genes showing expression changes. Genome Biology 15469. (doi:10.1186/s13059-014-0469-0)

Boland MJ, Nazor KL \& Loring JF 2014 Epigenetic regulation of pluripotency and differentiation. Circulation Research 115 311-324. (doi:10.1161/CIRCRESAHA.115.301517)

Bowyer SE, Rao AD, Lyle M, Sandhu S, Long GV, McArthur GA, Raleigh JM, Hicks RJ \& Millward M 2014 Activity of trametinib in K601E and L597Q BRAF mutation-positive metastatic melanoma. Melanoma Research 24 504-508. (doi:10.1097/ CMR.0000000000000099)

Brocks D, Assenov Y, Minner S, Bogatyrova O, Simon R, Koop C, Oakes C, Zucknick M, Lipka DB, Weischenfeldt J, et al. 2014 Intratumor DNA methylation heterogeneity reflects clonal evolution in aggressive prostate cancer. Cell Reports 8 798-806. (doi:10.1016/j. celrep.2014.06.053)

Cancer Genome Atlas Research Network 2015 The molecular taxonomy of primary prostate cancer. Cell 163 1011-1025. (doi:10.1016/j. cell.2015.10.025)

Chaligne R \& Heard E 2014 X-chromosome inactivation in development and cancer. FEBS Letters $\mathbf{5 8 8}$ 2514-2522. (doi:10.1016/j. febslet.2014.06.023)

Published by Bioscientifica Ltc 
Consortium F, the RIKEN PMI, CLST, Forrest AR, Kawaji H, Rehli M, Baillie JK, de Hoon MJ, Haberle V, Lassmann T, et al. 2014 A promoter-level mammalian expression atlas. Nature 507 462-470. (doi:10.1038/nature13182)

Cowley M, Wood AJ, Bohm S, Schulz R \& Oakey RJ 2012 Epigenetic control of alternative mRNA processing at the imprinted Herc3/ Nap115 locus. Nucleic Acids Research 40 8917-8926. (doi:10.1093/nar/ gks654)

Dahlman KB, Xia J, Hutchinson K, Ng C, Hucks D, Jia P, Atefi M, Su Z, Branch S, Lyle PL, et al. 2012 BRAF(L597) mutations in melanoma are associated with sensitivity to MEK inhibitors. Cancer Discovery 2 791-797. (doi:10.1158/2159-8290.CD-12-0097)

Day TK \& Bianco-Miotto T 2013 Common gene pathways and families altered by DNA methylation in breast and prostate cancers. Endocrine-Related Cancer 20 R215-R232. (doi:10.1530/ERC-13-0204)

Deaton AM \& Bird A 2011 CpG islands and the regulation of transcription. Genes and Development 25 1010-1022. (doi:10.1101/ gad.2037511)

Di Giammartino DC, Nishida K \& Manley JL 2011 Mechanisms and consequences of alternative polyadenylation. Molecular Cell $\mathbf{4 3}$ 853-866. (doi:10.1016/j.molcel.2011.08.017)

Elkon R, Ugalde AP \& Agami R 2013 Alternative cleavage and polyadenylation: extent, regulation and function. Nature Reviews Genetics 14 496-506. (doi:10.1038/nrg3482)

Epstein JI, Partin AW, Sauvageot J \& Walsh PC 1996 Prediction of progression following radical prostatectomy. A multivariate analysis of 721 men with long-term follow-up. American Journal of Surgical Pathology 20 286-292. (doi:10.1097/00000478-199603000-00004)

Flavahan WA, Drier Y, Liau BB, Gillespie SM, Venteicher AS, StemmerRachamimov AO, Suva ML \& Bernstein BE 2016 Insulator dysfunction and oncogene activation in IDH mutant gliomas. Nature 529 110-114. (doi:10.1038/nature16490)

Gelfman S, Cohen N, Yearim A \& Ast G 2013 DNA-methylation effect on cotranscriptional splicing is dependent on GC architecture of the exon-intron structure. Genome Research 23 789-799. (doi:10.1101/ gr.143503.112)

Gonzalgo ML, Nakayama M, Lee SM, De Marzo AM \& Nelson WG 2004 Detection of GSTP1 methylation in prostatic secretions using combinatorial MSP analysis. Urology 63 414-418. (doi:10.1016/j. urology.2003.08.039)

Guo Z, Yang X, Sun F, Jiang R, Linn DE, Chen H, Chen H, Kong X, Melamed J, Tepper CG, et al. 2009 A novel androgen receptor splice variant is up-regulated during prostate cancer progression and promotes androgen depletion-resistant growth. Cancer Research 69 2305-2313. (doi:10.1158/0008-5472.CAN-08-3795)

Han W, Shi M \& Spivack SD 2013 Site-specific methylated reporter constructs for functional analysis of DNA methylation. Epigenetics $\mathbf{8}$ 1176-1187. (doi:10.4161/epi.26195)

He YF, Li BZ, Li Z, Liu P, Wang Y, Tang Q, Ding J, Jia Y, Chen Z, Li L, et al. 2011 Tet-mediated formation of 5-carboxylcytosine and its excision by TDG in mammalian DNA. Science 333 1303-1307. (doi:10.1126/science.1210944)

Heintzman ND \& Ren B 2009 Finding distal regulatory elements in the human genome. Current Opinion in Genetics and Development 19 541-549. (doi:10.1016/j.gde.2009.09.006)

Heyn H, Vidal E, Ferreira HJ, Vizoso M, Sayols S, Gomez A, Moran S, Boque-Sastre R, Guil S, Martinez-Cardus A, et al. 2016 Epigenomic analysis detects aberrant super-enhancer DNA methylation in human cancer. Genome Biology 17 11. (doi:10.1186/s13059-016-0879-2)

Hu S, Wan J, Su Y, Song Q, Zeng Y, Nguyen HN, Shin J, Cox E, Rho HS, Woodard C, et al. 2013 DNA methylation presents distinct binding sites for human transcription factors. eLife 2 e00726. (doi:10.7554/ elife.00726)

Humphrey PA 2004 Gleason grading and prognostic factors in carcinoma of the prostate. Modern Pathology 17 292-306. (doi:10.1038/modpathol.3800054)
Illingworth RS \& Bird AP 2009 CpG islands - 'a rough guide'. FEBS Letters 583 1713-1720. (doi:10.1016/j.febslet.2009.04.012)

Ito S, Shen L, Dai Q, Wu SC, Collins LB, Swenberg JA, He C \& Zhang Y 2011 Tet proteins can convert 5-methylcytosine to 5-formylcytosine and 5-carboxylcytosine. Science 333 1300-1303. (doi:10.1126/ science.1210597)

Ji Z, Luo W, Li W, Hoque M, Pan Z, Zhao Y \& Tian B 2011 Transcriptional activity regulates alternative cleavage and polyadenylation. Molecular Systems Biology 7 534. (doi:10.1038/msb.2011.69)

Kaneda M, Okano M, Hata K, Sado T, Tsujimoto N, Li E \& Sasaki H 2004 Essential role for de novo DNA methyltransferase Dnmt3a in paternal and maternal imprinting. Nature 429 900-903. (doi:10.1038/nature02633)

Kangaspeska S, Stride B, Metivier R, Polycarpou-Schwarz M, Ibberson D, Carmouche RP, Benes V, Gannon F \& Reid G 2008 Transient cyclical methylation of promoter DNA. Nature 452 112-115. (doi:10.1038/ nature06640)

Katoh T, Yamano Y, Tsuji M \& Watanabe M 2008 Genetic polymorphisms of human cytosol glutathione S-transferases and prostate cancer. Pharmacogenomics 9 93-104. (doi:10.2217/14622416.9.1.93)

Klug M \& Rehli M 2006 Functional analysis of promoter CpG methylation using a CpG-free luciferase reporter vector. Epigenetics $\mathbf{1}$ 127-130. (doi:10.4161/epi.1.3.3327)

Lapuk AV, Volik SV, Wang Y \& Collins CC 2014 The role of mRNA splicing in prostate cancer. Asian Journal of Andrology 16 515-521. (doi:10.4103/1008-682X.127825)

Lawrence MG, Stephens CR, Need EF, Lai J, Buchanan G \& Clements JA 2012 Long terminal repeats act as androgen-responsive enhancers for the PSA-kallikrein locus. Endocrinology 153 3199-3210. (doi:10.1210/en.2012-1267)

Lei H, Oh SP, Okano M, Juttermann R, Goss KA, Jaenisch R \& Li E 1996 De novo DNA cytosine methyltransferase activities in mouse embryonic stem cells. Development 122 3195-3205.

Leick MB, Shoff CJ, Wang EC, Congress JL \& Gallicano GI 2012 Loss of imprinting of IGF2 and the epigenetic progenitor model of cancer. American Journal of Stem Cells 1 59-74.

Li E, Bestor TH \& Jaenisch R 1992 Targeted mutation of the DNA methyltransferase gene results in embryonic lethality. Cell 69 915-926. (doi:10.1016/0092-8674(92)90611-F)

Li L, Wang D, Xue M, Mi X, Liang Y \& Wang P 2014 3'UTR shortening identifies high-risk cancers with targeted dysregulation of the ceRNA network. Science Reports 4 5406. (doi:10.1038/srep05406)

Licatalosi DD \& Darnell RB 2010 RNA processing and its regulation: global insights into biological networks. Nature Reviews Genetics $\mathbf{1 1}$ 75-87. (doi:10.1038/nrg2673)

Lin X, Tascilar M, Lee WH, Vles WJ, Lee BH, Veeraswamy R, Asgari $\mathrm{K}$, Freije D, van Rees B, Gage WR, et al. 2001 GSTP1 CpG island hypermethylation is responsible for the absence of GSTP1 expression in human prostate cancer cells. American Journal of Pathology 159 1815-1826. (doi:10.1016/S0002-9440(10)63028-3)

Lister R, Pelizzola M, Dowen RH, Hawkins RD, Hon G, Tonti-Filippini J, Nery JR, Lee L, Ye Z, Ngo QM, et al. 2009 Human DNA methylomes at base resolution show widespread epigenomic differences. Nature 462 315-322. (doi:10.1038/nature08514)

Lou S, Lee HM, Qin H, Li JW, Gao Z, Liu X, Chan LL, Kl Lam V, So WY, Wang Y, et al. 2014 Whole-genome bisulfite sequencing of multiple individuals reveals complementary roles of promoter and gene body methylation in transcriptional regulation. Genome Biology 15408. (doi:10.1186/s13059-014-0408-0)

Luco RF, Allo M, Schor IE, Kornblihtt AR \& Misteli T 2011 Epigenetics in alternative pre-mRNA splicing. Cell 144 16-26. (doi:10.1016/j. cell.2010.11.056)

Maatouk DM, Kellam LD, Mann MR, Lei H, Li E, Bartolomei MS \& Resnick JL 2006 DNA methylation is a primary mechanism for silencing postmigratory primordial germ cell genes in both germ cell

Published by Bioscientifica Ltd. 
and somatic cell lineages. Development 133 3411-3418. (doi:10.1242/ dev.02500)

Maeder ML, Angstman JF, Richardson ME, Linder SJ, Cascio VM, Tsai SQ, Ho QH, Sander JD, Reyon D, Bernstein BE, et al. 2013 Targeted DNA demethylation and activation of endogenous genes using programmable TALE-TET1 fusion proteins. Nature Biotechnology 31 1137-1142. (doi:10.1038/nbt.2726)

Marina RJ, Sturgill D, Bailly MA, Thenoz M, Varma G, Prigge MF, Nanan KK, Shukla S, Haque N \& Oberdoerffer S 2016 TET-catalyzed oxidation of intragenic 5-methylcytosine regulates CTCF-dependent alternative splicing. EMBO Journal 35 335-355. (doi:10.15252/embj.201593235)

Massie CE, Mills IG \& Lynch AG 2016 The importance of DNA methylation in prostate cancer development. Journal of Steroid Biochemistry and Molecular Biology [in press]. (doi:10.1016/j. jsbmb.2016.04.009)

Maunakea AK, Chepelev I, Cui K \& Zhao K 2013 Intragenic DNA methylation modulates alternative splicing by recruiting MeCP2 to promote exon recognition. Cell Research 23 1256-1269. (doi:10.1038/cr.2013.110)

Maunakea AK, Nagarajan RP, Bilenky M, Ballinger TJ, D'Souza C, Fouse SD, Johnson BE, Hong C, Nielsen C, Zhao Y, et al. 2010 Conserved role of intragenic DNA methylation in regulating alternative promoters. Nature 466 253-257. (doi:10.1038/nature09165)

Metivier R, Gallais R, Tiffoche C, Le Peron C, Jurkowska RZ, Carmouche RP, Ibberson D, Barath P, Demay F, Reid G, et al. 2008 Cyclical DNA methylation of a transcriptionally active promoter. Nature 452 45-50. (doi:10.1038/nature06544)

Moarii M, Boeva V, Vert JP \& Reyal F 2015 Changes in correlation between promoter methylation and gene expression in cancer. BMC Genomics 16 873. (doi:10.1186/s12864-015-1994-2)

Nagarajan RP, Zhang B, Bell RJ, Johnson BE, Olshen AB, Sundaram V, Li D, Graham AE, Diaz A, Fouse SD, et al. 2014 Recurrent epimutations activate gene body promoters in primary glioblastoma. Genome Reseach 24 761-774. (doi:10.1101/gr.164707.113)

Okano M, Xie S \& Li E 1998 Cloning and characterization of a family of novel mammalian DNA (cytosine-5) methyltransferases. Nature Genetics 19 219-220. (doi:10.1038/890)

Pan CC, Potter SR, Partin AW \& Epstein JI 2000 The prognostic significance of tertiary Gleason patterns of higher grade in radical prostatectomy specimens: a proposal to modify the Gleason grading system. Amercian Journal of Surgical Pathology 24 563-569. (doi:10.1097/00000478-200004000-00011)

Papp B \& Plath K 2013 Epigenetics of reprogramming to induced pluripotency. Cell 152 1324-1343. (doi:10.1016/j.cell.2013.02.043)

Parry L \& Clarke AR 2011 The roles of the methyl-CpG binding proteins in cancer. Genes and Cancer 2 618-630. (doi:10.1177/1947601911418499)

Penney KL, Stampfer MJ, Jahn JL, Sinnott JA, Flavin R, Rider JR, Finn S, Giovannucci E, Sesso HD, Loda M, et al. 2013 Gleason grade progression is uncommon. Cancer Research 73 5163-5168. (doi:10.1158/0008-5472.CAN-13-0427)

Perini G, Diolaiti D, Porro A \& Della Valle G 2005 In vivo transcriptional regulation of N-Myc target genes is controlled by E-box methylation. PNAS 102 12117-12122. (doi:10.1073/pnas.0409097102)

Pertega-Gomes N, Vizcaino JR, Felisbino S, Warren AY, Shaw G, Kay J, Whitaker H, Lynch AG, Fryer L, Neal DE, et al. 2015 Epigenetic and oncogenic regulation of SLC16A7 (MCT2) results in protein overexpression, impacting on signalling and cellular phenotypes in prostate cancer. Oncotarget 6 21675-21684. (doi:10.18632/oncotarget.4328)

Pott S \& Lieb JD 2015 What are super-enhancers? Nature Genetics 47 8-12. (doi:10.1038/ng.3167)

Robinson D, Van Allen EM, Wu YM, Schultz N, Lonigro RJ, Mosquera JM, Montgomery B, Taplin ME, Pritchard CC, Attard G, et al. 2015 Integrative clinical genomics of advanced prostate cancer. Cell 161 1215-1228. (doi:10.1016/j.cell.2015.05.001)

Schroder FH, Hugosson J, Roobol MJ, Tammela TL, Ciatto S, Nelen V, Kwiatkowski M, Lujan M, Lilja H, Zappa M, et al. 2012 Prostatecancer mortality at 11 years of follow-up. New England Journal of Medicine 366 981-990. (doi:10.1056/NEJMoa1113135)

Serre D, Lee BH \& Ting AH 2010 MBD-isolated Genome Sequencing provides a high-throughput and comprehensive survey of DNA methylation in the human genome. Nucleic Acids Research $\mathbf{3 8}$ 391-399. (doi:10.1093/nar/gkp992)

Shlyueva D, Stampfel G \& Stark A 2014 Transcriptional enhancers: from properties to genome-wide predictions. Nature Reviews Genetics $\mathbf{1 5}$ 272-286. (doi:10.1038/nrg3682)

Shukla S, Kavak E, Gregory M, Imashimizu M, Shutinoski B, Kashlev M, Oberdoerffer P, Sandberg R \& Oberdoerffer S 2011 CTCF-promoted RNA polymerase II pausing links DNA methylation to splicing. Nature 479 74-79. (doi:10.1038/nature10442)

Siegel RL, Miller KD \& Jemal A 2015 Cancer statistics, 2015. CA: A Cancer Journal for Clinicians 65 5-29. (doi:10.3322/caac.21254)

Singer M, Kosti I, Pachter L \& Mandel-Gutfreund Y 2015 A diverse epigenetic landscape at human exons with implication for expression. Nucleic Acids Research 43 3498-3508. (doi:10.1093/nar/gkv153)

Soejima H \& Higashimoto K 2013 Epigenetic and genetic alterations of the imprinting disorder Beckwith-Wiedemann syndrome and related disorders. Journal of Human Genetics $\mathbf{5 8}$ 402-409. (doi:10.1038/ jhg.2013.51)

Stamey TA, McNeal JE, Yemoto CM, Sigal BM \& Johnstone IM 1999 Biological determinants of cancer progression in men with prostate cancer. JAMA 281 1395-1400. (doi:10.1001/jama.281.15.1395)

Taberlay PC, Statham AL, Kelly TK, Clark SJ \& Jones PA 2014 Reconfiguration of nucleosome-depleted regions at distal regulatory elements accompanies DNA methylation of enhancers and insulators in cancer. Genome Research 24 1421-1432. (doi:10.1101/gr.163485.113)

Tahiliani M, Koh KP, Shen Y, Pastor WA, Bandukwala H, Brudno Y, Agarwal S, Iyer LM, Liu DR, Aravind L, et al. 2009 Conversion of 5-methylcytosine to 5-hydroxymethylcytosine in mammalian DNA by MLL partner TET1. Science 324 930-935. (doi:10.1126/science.1170116)

Valdes-Mora F \& Clark SJ 2015 Prostate cancer epigenetic biomarkers: next-generation technologies. Oncogene 34 1609-1618. (doi:10.1038/ onc.2014.111)

Wang H, Maurano MT, Qu H, Varley KE, Gertz J, Pauli F, Lee K, Canfield T, Weaver M, Sandstrom R, et al. 2012 Widespread plasticity in CTCF occupancy linked to DNA methylation. Genome Research 22 1680-1688. (doi:10.1101/gr.136101.111)

Wood AJ, Schulz R, Woodfine K, Koltowska K, Beechey CV, Peters J, Bourc'his D \& Oakey RJ 2008 Regulation of alternative polyadenylation by genomic imprinting. Genes and Development 22 1141-1146. (doi:10.1101/gad.473408)

Yamashita R, Sathira NP, Kanai A, Tanimoto K, Arauchi T, Tanaka Y, Hashimoto S, Sugano S, Nakai K \& Suzuki Y 2011 Genome-wide characterization of transcriptional start sites in humans by integrative transcriptome analysis. Genome Research 21 775-789. (doi:10.1101/gr.110254.110)

Yao L, Shen H, Laird PW, Farnham PJ \& Berman BP 2015 Inferring regulatory element landscapes and transcription factor networks from cancer methylomes. Genome Biology 16 105. (doi:10.1186/ s13059-015-0668-3)

Yearim A, Gelfman S, Shayevitch R, Melcer S, Glaich O, Mallm JP, Nissim-Rafinia M, Cohen AH, Rippe K, Meshorer E, et al. 2015 HP1 is involved in regulating the global impact of DNA methylation on alternative splicing. Cell Reports 10 1122-1134. (doi:10.1016/j. celrep.2015.01.038)

Received in final form 5 September 2016

Accepted 7 September 2016

Accepted Preprint published online 7 September 2016 http://erc.endocrinology-journals.org

DOI: 10.1530/ERC-16-0306
(C) 2016 Society for Endocrinology Printed in Great Britain 